\title{
Multifunctional upconversion-nanoparticles- trismethylpyridylporphyrin-fullerene nanocomposite: a near-infrared light-triggered theranostic platform for imaging-guided photodynamic therapy
}

\author{
Mirong Guan ${ }^{1}$, Hao Dong ${ }^{2}$, Jiechao Ge ${ }^{3}$, Daiqin Chen ${ }^{1}$, Lingdong Sun ${ }^{2}$, Shumu $\mathrm{Li}^{1}$, Chunru Wang ${ }^{1}$, \\ Chunhua $\mathrm{Yan}^{2}$, Pengfei Wang ${ }^{3}$ and Chunying Shu ${ }^{1}$
}

Photodynamic therapy (PDT) is an excellent therapeutic modality for various malignant and nonmalignant cancers. This approach utilizes reactive oxygen species generated through the reaction between photosensitizer and oxygen in tissues upon light irradiation to achieve effective treatment. However, limited penetration depth and oxygen-deficient microenvironment hinder the efficiency of PDT. In this work, we design a multifunctional near-infrared (NIR)-triggered theranostic agent based on upconversion-nanoparticles-Polyoxyethylene bis (amine)-trismethylpyridylporphyrin-fullerene nanocomposite (UCNP-PEG-FA/ $\mathrm{PC}_{70}$ ) for imaging (fluorescence/upconversion luminescence/magnetic resonance imaging)-guided photodynamic therapy. In this multimodal nanocompsite, UCNPs are employed as light transducers to convert NIR light into ultraviolet-visible light to activate $\mathrm{PC}_{70}$ to generate singlet oxygen $\left({ }^{1} \mathrm{O}_{2}\right)$ even under low-oxygen conditions. Meanwhile, the upconversion emission, magnetic resonance imaging and fluorescence signal coming from UCNPs and $\mathrm{PC}_{70}$ nanocomposite enable UCNP-PEG-FA/PC 70 to act as a multimodal imaging diagnostic agent, which facilitates the imaging-guided PDT. Furthermore, folate-mediated active targeting would enhance the accumulation of multifunctional hybrid in tumor. In vitro as well as in vivo results suggest that this smart nanocomposite is promising as an NIR light-triggered and -targeted theranostic platform for imaging-guided PDT of cancer, which may provide a solution to the bottleneck problems of PDT, namely, limited penetration depth and oxygen-deficient microenvironment.

NPG Asia Materials (2015) 7, e205; doi:10.1038/am.2015.82; published online 31 July 2015

\section{INTRODUCTION}

Theranostic nanoparticles, which combine both therapeutic and diagnostic capabilities in one nanoplatform, have potential to propel the biomedical field toward personalized medicine. ${ }^{1-3}$ Specifically, phototriggered theranostics, combining phototherapies (for example, photodynamic, $^{4,5}$ photothermal, ${ }^{6,7}$ and phototriggered chemo ${ }^{8,9}$ / gene therapy ${ }^{10}$ ) with real-time photodiagnostics (for example, bioluminescence, ${ }^{11}$ fluorescence, ${ }^{12,13}$ and photoacoustic imaging ${ }^{14,15}$ ) have been actively pursued due to the advantages of spatiotemporal selectivity, non-ionizing radiation and specificity for disease destruction. Among them, near-infrared (NIR) light-triggered photodynamic theranostics, in which nanoparticles are used as photodynamic therapy (PDT) agents, have recently been receiving much attention due to deep penetration and simultaneous generation of reactive oxygen species (ROS) upon the NIR light irradiation, leading to ablation of cancer cells as a result. Up to date, several nanocomposites including gold nanocomposites, ${ }^{16-19}$ carbon nanostructures, ${ }^{20,21} \quad \mathrm{~W}_{18} \mathrm{O}_{49}{ }^{22}$ $\mathrm{WS}_{2},{ }^{23}$ porphyrin-functionalized porous nanoparticles, ${ }^{24}$ and upconversion nanoparticles (UCNPs) ${ }^{25}$ as NIR light-triggered photodynamic theranostic nanoplatforms have shown efficacy in vitro and in vivo studies. Wherein, NIR light-triggered photodynamic theranostics based on lanthanide-doped UCNPs has been well investigated for biomedical uses due to their intrinsic anti-Stokes upconversion luminescent properties. ${ }^{26-28}$ Compared with traditional optical biomarkers, such as quantum dots and organic dyes, UCNPs exhibit excellent photostability, low background autofluorescence, remarkable penetration depth and high conversion efficiency for NIR photons into visible and ultraviolet (UV) ones, which lead to its unique superiority for bioimaging and bioassay studies. ${ }^{29,30}$ In particular, $\mathrm{NaGdF}_{4}$-based UCNPs have been developed as multimodal imaging probes for

${ }^{1}$ Key Laboratory of Molecular Nanostructure and Nanotechnology, Institute of Chemistry, Chinese Academy of Sciences, and Beijing National Laboratory for Molecular Sciences, Beijing, China; ${ }^{2}$ Beijing National Laboratory for Molecular Sciences, State Key Laboratory of Rare Earth Materials Chemistry and Applications, PKU-HKU Joint Laboratory in Rare Earth Materials and Bioinorganic Chemistry, College of Chemistry and Molecular Engineering, Peking University, Beijing, China and ${ }^{3}$ Key Laboratory of Photochemical Conversion and Optoelectronic Materials, Technical Institute of Physics and Chemistry (TIPC), Chinese Academy of Sciences, Beijing, China

Correspondence: Dr C Shu, Key Laboratory of Molecular Nanostructure and Nanotechnology, Institute of Chemistry, Chinese Academy of Sciences, No. 2, Zhongguancun North First Street, Haidian District, Beijing 100190, China.

E-mail: shucy@iccas.ac.cn

Received 6 March 2015; revised 17 May 2015; accepted 25 May 2015 
upconversion luminescence (UCL) imaging and magnetic resonance imaging (MRI) modality. ${ }^{31}$ Such multifunctional nanomaterials offer synergetic advantages of UCL imaging, that is, deep penetration and high sensitivity, along with the anatomic imaging capability of MRI in high spatial resolution. ${ }^{31}$ Benefiting from the UV and visible emissions on specific NIR excitation, UCNPs have also been employed as light transducers to activate photosensitizers. UCNP-based PDT nanocomposites are considered promising platforms for cancer therapy due to the non-invasive manner and deep tissue penetration of NIR light, which breaks the dilemma of using UV or visible lights as irradiation source. Since Zhang et al. ${ }^{32}$ first demonstrated the application of UCNP-based nanocomposite for PDT of bladder cancer cells, recent advances in the integration of UCNPs with PSs such as chlorin e6, Rose Bengal, and IR825 (an NIR-absorbing dye) for their PDT applications in vitro and in vivo have created many excitements. ${ }^{33-35}$ However, the phototoxic effect of ${ }^{1} \mathrm{O}_{2}$ on PDT is restricted because of a hypoxic condition in tumor tissue. ${ }^{36}$ Therefore, it is important to develop NIR light-triggered and -targeted theranostic platform for imaging-guided PDT of cancer under low-oxygen conditions.

Porphyrins as most common used PSs have been approved by Food and Drug Administration for treatment of various non-malignancies and malignancies. They have excellent photophysical properties, such as stronger absorption bands and high singlet oxygen quantum yield because of their large $\pi$-conjugated aromatic domains. Strong fluorescence of porphyrin also can be used as imaging probe to monitor the pharmacokinetics. ${ }^{37}$ Very recently, trismethylpyridylporphyrin- $\mathrm{C}_{70}$ $\left(\mathrm{PC}_{70}\right)$ dyad has been reported to act as a promising photosensitizer for its reasonable water dispersibility, high photostability and favorable biocompatibility. ${ }^{38}$ Significantly, the present $\mathrm{PC}_{70}$ exhibits extraordinary PDT efficiency in vitro even under low-oxygen conditions due to its extremely long lifetime triplet state $(211.3 \mu \mathrm{s}) .{ }^{38}$ Unfortunately, the UV-to-blue excitation of $\mathrm{PC}_{70}$ hinders the enhancement of PDT efficiency in vivo due to the limited penetration depth of UV-to-blue irradiation. The introduction of UCNPs may pave the way for the application of $\mathrm{PC}_{70}$ as a NIR light-triggered PDT agent in vivo since UCNPs can serve as phototransducers by absorbing NIR light to activate $\mathrm{PC}_{70}$ to generate ${ }^{1} \mathrm{O}_{2}$. In addition, the involved UCNPs may reduce the effect by energy transfer from UCNPs to porphyrin, ${ }^{38}$ and recover part of the quenched fluorescence of porphyrin. ${ }^{37}$

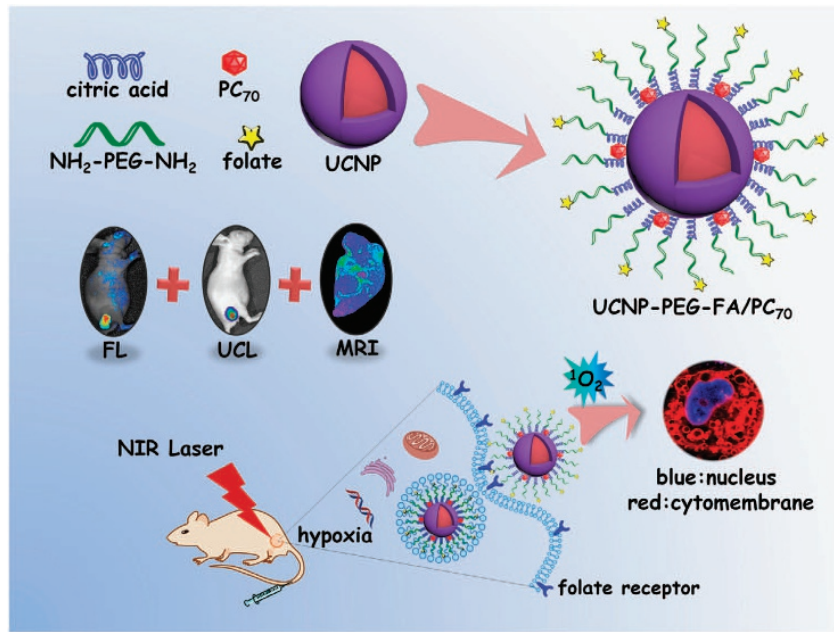

Figure 1 Schematic strategies of trimodal imaging guided UCNP-PEG-FA/ $\mathrm{PC}_{70}$ (upconversion-nanoparticles-trismethylpyridylporphyrin-fullerene nanocomposite) for photodynamic therapy.
Herein, we design a multifunctional theranostic nanoplatform based on UCNPs/PC 70 nanocomposite for NIR-triggered fluorescence/UCL/ MR trimodal imaging and simultaneous PDT both in vitro and in vivo (Figure 1). To match the UV-to-blue absorption of $\mathrm{PC}_{70}$ for high efficiency of PDT, $\beta-\mathrm{NaGdF}_{4}: \mathrm{Yb}, \mathrm{Tm} @ \mathrm{NaGdF}_{4}$ core/shell nanoparticles were rationally designed. Subsequently, $\mathrm{PC}_{70}$ was decorated on the surface of UCNPs through electrostatic interaction. Finally, the UCNPs/PC 70 nanocomposite was coated with folic acid-modified PEG for active targeting and prolonged circulation time. With such a UCNP-PEG-FA/PC 70 nanocomposite, trimodal imaging of FL/UCL/ MR can be used to guide the PDT treatment of cancer cells efficiently in vitro and in vivo via the activation of $\mathrm{PC}_{70}$ by $\mathrm{UV}$ and blue emissions from UCNPs. Besides, folate as a target element can enhance accumulation of nanocomposite in tumor to improve the efficiency of PDT. Most importantly, the synthesized UCNP-PEG-FA/ $\mathrm{PC}_{70}$ may provide solutions to the bottleneck problems of PDT, namely, limited penetration depth and oxygen-deficient microenvironment.

\section{MATERIALS AND METHODS}

\section{Instruments}

Samples for transmission electron microscopy (TEM) analysis were prepared by drying a colloidal solution containing nanoparticles on amorphous carboncoated copper grids. Low-resolution TEM was operated on a JEOL-JEM 2100 transmission electron microscope at $200 \mathrm{kV}$. High-resolution TEM was carried out on a JEOL-JEM 2100F field emission transmission electron microscope at $200 \mathrm{kV}$. Powder X-ray diffraction patterns were recorded on a Rigaku D/MAX-2000 diffractometer (Tokyo, Japan) with a slit of $1 / 2^{\circ}$ at a scanning rate of $2^{\circ} \mathrm{min} / \mathrm{min}$, using $\mathrm{Cu} \mathrm{K \alpha}$ radiation $(\lambda=0.5406 \AA)$. Upconversion emission spectra were recorded on a Hitachi F-4500 spectrometer, with the Photomultiplier tubes (PMT) voltage of $700 \mathrm{~V}$. The particle size and zeta potential were determined by dynamic light scattering using Malvern Nano-ZS90 apparatus (Malvern Instruments, Worcestershire, UK). Absorbance measurements were carried out using UV2550 spectrophotometer (SHIMADZU, Shimane, Japan). Fluorescence spectra were acquired though Fluorolog spectrophotometer. IR spectra were measured using Thermo instrument (NICOLET In10 MX, Shanghai, China).

\section{Materials}

$\mathrm{NH}_{2}$-PEG3000- $\mathrm{NH}_{2}$ and folate were purchased from Innochem (Beijing, China). 1,10-Diamino-4,7-dioxadecane, 1-ethyl-3-(3-dimethylaminopropyl)carbodiimide hydrochloride (EDC) and $\mathrm{N}$-hydroxysuccinimide (NHS) were purchased from Acros (Shanghai, China). The culture medium Dulbecco's modified Eagle's medium (Invitrogen, Shanghai, China) supplemented with $10 \%$ fetal bovine serum (Hyclone Company, South Logan, UT, USA), penicillin $\left(100 \mu \mathrm{g} \mathrm{ml}^{-1}\right)$ and streptomycin $\left(100 \mu \mathrm{g} \mathrm{ml}^{-1}\right)$ (Gibco, Grand Island, NY, USA). Dil, MitoRed, Lyso, PI and Hoechst 33258 were purchased from PuJingKangLi (Beijing, China). All other chemicals used were analytical reagents.

\section{Synthesis of $\boldsymbol{\beta}-\mathrm{NaGdF}_{4}: \mathrm{Yb}, \mathrm{Tm} @ \mathrm{NaGdF}_{4}$}

The $\beta-\mathrm{NaGdF}_{4}: \mathrm{Yb}$,Tm@NaGdF 4 core/shell nanoparticles were synthesized with a modified thermolysis method. Three steps are included as following.

Synthesis of $\alpha-\mathrm{NaGdF}_{4}: \mathrm{Yb}, \mathrm{Tm}$ nanoparticles ( $\alpha$-core). A given amount of $\mathrm{Ln}$ $\left(\mathrm{CF}_{3} \mathrm{COO}\right)_{3}(1 \mathrm{mmol}), 0.29 \mathrm{mmol} \mathrm{Gd}\left(\mathrm{CF}_{3} \mathrm{COO}\right)_{3}, 0.70 \mathrm{mmol} \mathrm{Yb}\left(\mathrm{CF}_{3} \mathrm{COO}\right)_{3}$, and $0.01 \mathrm{mmol} \mathrm{Tm}\left(\mathrm{CF}_{3} \mathrm{COO}\right)_{3}$, and $\mathrm{CF}_{3} \mathrm{COONa}(1 \mathrm{mmol})$ were added to a mixture containing oleic acid (OA), oleylamine (OM), and octadecene (ODE) $(40 \mathrm{mmol}$, molar ratio: 1:1:2) into a three-necked flask $(100 \mathrm{ml})$ at room temperature. The slurry was heated to $110^{\circ} \mathrm{C}$ to remove low-boiling water, and oxygen with vigorous stirring under vacuum. Then, the solution was heated to $310^{\circ} \mathrm{C}$ at a heating rate of $15^{\circ} \mathrm{C} \mathrm{min}^{-1}$ and kept for $15 \mathrm{~min}$ under $\mathrm{N}_{2}$ atmosphere. After cooling to room temperature, the nanoparticles were collected with centrifugation (7800 r.p.m., $10 \mathrm{~min}$ ) after precipitation by adding 
excess amount of ethanol. The final product was dispersed in $10 \mathrm{ml}$ of cyclohexane.

Synthesis of $\beta$-NaGdF $4: \mathrm{Yb}, \mathrm{Tm}$ nanoparticles ( $\beta$-core). Five milliliter of as-prepared $\alpha-\mathrm{NaGdF}_{4}: \mathrm{Yb}, \mathrm{Tm}$ nanoparticles were redispersed in a mixture of $\mathrm{OA}$ and $\mathrm{ODE}(40 \mathrm{mmol}$, molar ratio: $1: 1)$. Then, $\mathrm{Ln}\left(\mathrm{CF}_{3} \mathrm{COO}\right)_{3}(0.5 \mathrm{mmol}$, $0.145 \mathrm{mmol} \mathrm{Gd}\left(\mathrm{CF}_{3} \mathrm{COO}\right)_{3}, 0.35 \mathrm{mmol} \mathrm{Yb}\left(\mathrm{CF}_{3} \mathrm{COO}\right)_{3}$, and $0.005 \mathrm{mmol} \mathrm{Tm}$ $\left.\left(\mathrm{CF}_{3} \mathrm{COO}\right)_{3}\right)$, and $\mathrm{CF}_{3} \mathrm{COONa}(0.5 \mathrm{mmol})$ were added. After removing low boiling cyclohexane, water and oxygen with vigorous stirring under vacuum, the mixture was then heated to $325^{\circ} \mathrm{C}$ at a heating rate of $15^{\circ} \mathrm{C} \mathrm{min}^{-1}$ and kept for 60 min under $\mathrm{N}_{2}$ atmosphere. Then, the reaction was cooled to room temperature. Excess amount of ethanol was added to precipitate the nanoparticles, which was collected by further centrifugation (7800 r.p.m., $10 \mathrm{~min}$ ) and redispersed in $10 \mathrm{ml}$ of cyclohexane.

Synthesis of $\beta$ - $N a G d F_{4}: Y b, T m @ N a G d F_{4}$ nanoparticles ( $\beta$-core@shell). Five milliliter of as-prepared $\beta-\mathrm{NaGdF}_{4}: \mathrm{Yb}$,Tm nanoparticles were redispersed in a mixture of $\mathrm{OA}$ and $\mathrm{ODE}(40 \mathrm{mmol}$, molar ratio: $1: 1)$. Then, $\mathrm{Gd}\left(\mathrm{CF}_{3} \mathrm{COO}\right)_{3}$ $(1 \mathrm{mmol})$ and $\mathrm{CF}_{3} \mathrm{COONa}(1 \mathrm{mmol})$ were added. The slurry was heated to $110^{\circ} \mathrm{C}$ to remove low boiling cyclohexane, water, and oxygen with vigorous stirring under vacuum. Then, the solution was heated to $320^{\circ} \mathrm{C}$ at a heating rate of $15^{\circ} \mathrm{C} \mathrm{min}^{-1}$ and kept for $40 \mathrm{~min}$ under $\mathrm{N}_{2}$ atmosphere. After cooling to room temperature, the nanoparticles were collected with centrifugation (7800 r.p.m., $10 \mathrm{~min}$ ) after precipitation by adding excess amount of ethanol. The final product was dispersed in $5 \mathrm{ml}$ of cyclohexane.

\section{Preparation of citric acid modified nanoparticles (citric-UCNP)}

One milliliter cyclohexane dispersions containing hydrophobic nanoparticles were precipitated with ethanol by centrifugation and redispersed in $5 \mathrm{ml}$ of chloroform. Citric acid $(200 \mathrm{mg})$ was dissolved in $5 \mathrm{ml}$ of deionized water. The $\mathrm{pH}$ value of the citric acid solution was tuned $\sim 7$ by ammonia. Subsequently, the two solutions were mixed under vigorous stirring at room temperature overnight. After that, the chloroform phase was deserted, whereas the water phase was transferred to a centrifuge tube. Citric acid-modified UCNPs were collected after high-speed centrifugation at 18000 r.p.m. for $15 \mathrm{~min}$ and then washed with water for several times. Finally, the products were redispersed in water.

\section{Synthesis of folate-NH-PEG3000- $\mathrm{NH}_{2}$}

Folate-NH-PEG3000- $\mathrm{NH}_{2}$ conjugate was synthesized according to the previous method. Briefly, folate was activated with EDC and NHS at a 1:2:2 molar ratio in dimethyl sulfoxide for $2 \mathrm{~h}$. Under nitrogen atmosphere, folate was filtered with a syringe filter (pore size: $0.2 \mu \mathrm{m}$ ). A hetero-bifunctional poly (ethylene glycol) derivate $\left(\mathrm{NH}_{2}-\mathrm{PEG} 3000-\mathrm{NH}_{2} \mathrm{Mw} 3000\right)$ was added to the above solution at a molar ratio of 15:1 (folate:PEG). After reaction for $4 \mathrm{~h}$ under nitrogen atmosphere, the reactants were precipitated with acetone and centrifuged to remove the folate residue. Folate-NH-PEG3000- $\mathrm{NH}_{2}$ conjugation in the supernatant was dialyzed against deionized water.

\section{Synthesis of UCNP-ca/PC 70 (UCNP/PC 70$)$}

Citric-UCNP $(37.6 \mathrm{mg})$ was dispersed in water $(10 \mathrm{ml})$. Then $18.8 \mathrm{mg}$ of $\mathrm{PC}_{70}$ was added into the above solution and stirred overnight to obtain UCNP/PC ${ }_{70}$.

\section{Synthesis of UCNP-NH-PEG3000-NH-folate/PC 70 (UCNP-PEG-FA/PC 70 )}

Fifteen milligram of EDC and $8.5 \mathrm{mg}$ of NHS were added into the above $\mathrm{UCNP} / \mathrm{PC}_{70}$ solution and stirred for $2 \mathrm{~h}$. Then, folate-NH-PEG3000- $\mathrm{NH}_{2}$ (500 mg) was added into the above solution, followed by vigorous stirring for $24 \mathrm{~h}$. The nanoparticles were dialyzed by deionized water for 1 week.

\section{Synthesis of $\mathrm{PC}_{70}$}

In brief, terephthalaldehydic acid methyl ester, pyridine-4-aldehyde and pyrrole were reacted in propionic acid for $1.5 \mathrm{~h}$, and the resultant mixture was separated through a silica gel. Then $\mathrm{LiAlH}_{4}$ was used to reduce the ester group to primary hydroxyl group at room temperature. Subsequently a Swern oxidation reaction was applied to obtain aldehyde group, the final product was purified by silica gel column chromatography. After that, Prato reaction was carried out to obtain crude product which was subjected to silica gel column chromatography. The obtained final product was mixed with methyl tosylate and refluxed in argon atmosphere for $1 \mathrm{~h}$ and then passed through an anion-exchange resin repeatedly to yield $\mathrm{PC}_{70}$ as a chloride salt.

\section{Loading capacities and release behaviors $\mathrm{PC}_{70}$}

A gradient concentration $(4,8,12,16,20$ and $25 \%)$ of $\mathrm{PC}_{70}$ in UCNPs solutions was centrifuged at 5000 r.p.m. $\mathrm{min}^{-1}$ for $30 \mathrm{~min}$. $\mathrm{PC}_{70}$ loading content was calculated according to the following formula: $\mathrm{PC}_{70}$ loading content $=$ weight of $\mathrm{PC}_{70} /$ (weight of $\mathrm{PC}_{70}$ +weight of UCNPs). The release behavior of $\mathrm{PC}_{70}$ from the nanocomposites was evaluated in $10 \%$ fetal bovine serum. The resulting solution was filtrated through ultrafiltration $\left(\mathrm{M} . \mathrm{W}_{\text {cut }_{\mathrm{cuf}}}=10000\right)$ and the filtrate was detected by ultraviolet absorbance spectra.

\section{Detection of singlet oxygen from UCNP-PEG-FA/PC 70}

Water soluble disodium 9,10-anthracendipropionic acid ( $\left.\mathrm{Na}_{2}-\mathrm{ADPA}\right)$ was used as the ${ }^{1} \mathrm{O}_{2}$ trapping agent. In the experiments, $100 \mu \mathrm{l}$ of $\mathrm{Na}_{2}-\mathrm{ADPA}$ solution $\left(1 \mathrm{mg} \mathrm{ml}^{-1}\right)$ was added into $1.5 \mathrm{ml}$ of UCNP-PEG-FA/PC 70 solution and then exposed to 980 laser irradiation at a power density of $1 \mathrm{~W} \mathrm{~cm}^{-2}$. To eliminate the inner-filter effect, the maxima absorption of UCNP-PEG-FA/PC 70 was adjusted to about $0.2 \mathrm{OD}$. The absorption of $\mathrm{Na}_{2}-\mathrm{ADPA}$ from 380 to $420 \mathrm{~nm}$ was recorded at different irradiation times.

\section{In vitro $\mathrm{PDT}$}

The photo-cytotoxicity of UCNP-PEG-FA/PC 70 in vitro was carried out against luciferase-expression cervical cancer (HeLa-luc). Hela-luc cells were seeded in a 96-well plate with density of ca. $5 \times 10^{4}$ per well and cultured in $5 \% \mathrm{CO}_{2}$ at $37^{\circ} \mathrm{C}$ for $24 \mathrm{~h}$. Hela-luc cells were then treated with UCNP-PEG-FA/PC ${ }_{70}$ in different concentration gradients for $3 \mathrm{~h}$ in the dark, and then irradiated with a $980 \mathrm{~nm}$ laser for $10 \mathrm{~min}\left(0.8 \mathrm{~W} \mathrm{~cm}^{-2}, 1 \mathrm{~min}\right.$ break after $1 \mathrm{~min}$ irradiation) under air condition and nitrogen condition, respectively. Afterward, the aged medium was replaced with the fresh medium, and cells were cultivated for $24 \mathrm{~h}$ in the dark at $37^{\circ} \mathrm{C}$. Cytotoxicity was evaluated by a WST- 8 assay with a Cell Counting Kit-8 (CCK-8; DOJINDO, Kumamoto, Japan). A 96-well plate reader (iMarkmicroplate reader, Bio-RAD, Hercules, CA, USA) was used to determine cell viability. Hela-luc cells treated only with UCNP-PEG-FA/PC ${ }_{70}$ in the dark for $24 \mathrm{~h}$ were used as control. As for other controls, three kinds of cells including Hela-luc cells, A549 and HBE cells were treated with either UCNPPEG/PC $70\left(156 \mu \mathrm{g} \mathrm{ml}^{-1}\right)$ or $\mathrm{PC}_{70}\left(40 \mu \mathrm{g} \mathrm{ml}^{-1}, 23.8 \mu \mathrm{M}\right)$ and UCNP $(80$ $\mu \mathrm{g} \mathrm{ml}^{-1}$ ). Cell viability was then detected. To further confirm the targeting property of UCNP-PEG-FA/PC ${ }_{70}$, folate blocking experiment was done by preincubated Hela-luc, A549 and HBE cells with folate $\left(40 \mu \mathrm{g} \mathrm{ml}^{-1}\right)$ for $0.5 \mathrm{~h}$. The cells were further incubated with UCNP-PEG-FA/PC $70\left(200 \mu \mathrm{g} \mathrm{ml}^{-1}\right)$ for $3 \mathrm{~h}$. Afterward, the cell viability was detected by CCK-8. Corresponding results are expressed as mean \pm s.d.

\section{Cell imagings}

Hela-luc cells were incubated with UCNP-PEG-FA/PC $70 \quad\left(200 \mu \mathrm{g} \mathrm{ml}^{-1}\right)$ at $37^{\circ} \mathrm{C}, 5 \% \mathrm{CO}_{2}$ for $3 \mathrm{~h}$. The aged cell culture was replaced with the fresh Dulbecco's modified Eagle's medium (without phenol red). Subsequently, the cells were illuminated by an external $980 \mathrm{~nm}\left(0.8 \mathrm{~W} \mathrm{~cm}{ }^{-2}, 1\right.$ min break after $1 \mathrm{~min}$ irradiation) laser for $10 \mathrm{~min}$. Either Hoechst $33258\left(1 \mathrm{mg} \mathrm{ml}^{-1}, 5 \mu \mathrm{l}\right.$, incubated with cells for $20 \mathrm{~min})$, PI ( $1 \mathrm{mg} \mathrm{ml}^{-1}, 5 \mu \mathrm{l}$, incubated with cells for $15 \mathrm{~min})$, Dil ( $1 \mathrm{mg} \mathrm{ml}^{-1}, 5 \mu \mathrm{l}$, incubated with cells for $\left.20 \mathrm{~min}\right)$, MitoRed ( $1 \mathrm{mg} \mathrm{ml}^{-1}, 5 \mu \mathrm{l}$, incubated with cells for $30 \mathrm{~min}$ ), or Lyso $\left(1 \mathrm{mg} \mathrm{ml}^{-1}, 5 \mu \mathrm{l}\right.$, incubated with cells for $45 \mathrm{~min}$ ) was then added according to the actual conditions. The cells were washed with icy phosphate-buffered saline buffer for three times before observation. The images were obtained by FV 1000-IX81 confocal laser scanning microscope (Olympus, Miyazaki, Japan). The cells were dyed without laser irradiation as a control.

\section{In vivo $\mathrm{PDT}$}

Female Balb/c nude mice (16-20 g) were purchased from Center for Experimental Animals, Institute of Process Engineering, Chinese Academy of Science 
(Beijing, China). In vivo study conforms to the guidelines of The National Regulation of China for Care and Use of Laboratory Animals. The tumor model was established by subcutaneous injection of Hela/luc cells in the right buttock of each mouse. The tumors were allowed to grow for around 5 days to reach the size of ca. $30-60 \mathrm{~mm}^{3}$.

The tumor-bearing mice were randomized into six groups $(n=3$, each group). Group 1 was treated by intravenous injection with UCNP-PEG-FA/ $\mathrm{PC}_{70}$ at a dosage of $200 \mu \mathrm{l}\left(2 \mathrm{mg} \mathrm{ml}^{-1}\right)$. After $24 \mathrm{~h}$ post-injection, the tumor sites were irradiated with $980 \mathrm{~nm}$ NIR light for $3 \mathrm{~min}\left(0.7 \mathrm{~W} \mathrm{~cm}^{-2}, 30 \mathrm{~s}\right.$ break after $30 \mathrm{~s}$ irradiation). The other three groups were intravenously injected with UCNP-PEG-FA $\left(1.6 \mathrm{mg} \mathrm{ml}^{-1}, 200 \mu \mathrm{l}\right), \mathrm{PC}_{70}\left(0.4 \mathrm{mg} \mathrm{ml}^{-1}, 200 \mu \mathrm{l}\right)$, and saline $(200 \mu \mathrm{l})$, respectively, and followed the same procedure as controls. The fifth and sixth groups were treated with UCNP-PEG-FA/PC $70\left(2 \mathrm{mg} \mathrm{ml}^{-1}, 200 \mu \mathrm{l}\right)$ and saline $(200 \mu \mathrm{l})$ without laser irradiation as another control. All the groups were treated with only one injection. The body weights and tumor volumes were monitored every 2 days after treatment. The tumor volume was calculated using the following equation: tumor volume $(V)=$ length $\times$ width $^{2} / 2$. Relative tumor volume was calculated as $V / V_{0}$ ( $V_{0}$ was the corresponding tumor volume when the treatment was initiated).

\section{Trimodal FL/UCL/MR imaging in vivo}

Fluorescence imaging was performed on an in vivo imaging system (CRI Maestro 2) with a $600 \mathrm{~nm}$ laser as the excited source. The fluorescence images were corrected at 560-800 $\mathrm{nm}$ and analyzed with Maestro 2 software. The Balb/c nude mice were anesthetized with $1.5 \%$ pentobarbital sodium by intraperitoneal injection at dosage of $100 \mu \mathrm{l}$. UCNP-PEG-FA/PC 70 nanoparticles $\left(200 \mu \mathrm{l}, 2 \mathrm{mg} \mathrm{ml}^{-1}\right)$ were injected by intravenous injection, and fluorescence imaging was performed at timed intervals $(0,2,4,8,24$ and $72 \mathrm{~h})$.

In vivo UCL imaging experiments were performed with a CALIPER Lumina II in vivo imaging system with an adjustable $980 \mathrm{~nm}$ laser as the excited source for in vivo imaging. Before imaging, the Balb/c nude mice were anesthetized with $1.5 \%$ pentobarbital sodium by intraperitoneal injection at dosage of $100 \mu \mathrm{l}$. UCNP-PEG-FA/PC 70 nanocomposites $\left(200 \mu \mathrm{l}, 2 \mathrm{mg} \mathrm{ml}^{-1}\right)$ were injected by intravenous injection, and UCL imaging was performed after $24 \mathrm{~h}$ post-injection with exposure time of $0.3 \mathrm{~s}$.

The in vitro MR imaging experiments were performed in a $0.5 \mathrm{~T}$ MRI magnet (NM120-Analyst, Shanghai Niumag Corporation). UCNP-PEG-FA/ $\mathrm{PC}_{70}$ nanocomposites were dispersed in water at various $\mathrm{Gd}$ concentrations (by ICP measurement). $T_{1}$ was acquired using an inversion recovery sequence. Finally, the $r_{1}$ value was determined through the curve fitting of $1 / T_{1}$ relaxation time $\left(s^{-1}\right)$ versus the Gd concentration (mM).

In vivo $\mathrm{MR}$ imaging experiments were performed on a $7 \mathrm{~T}$ MRI scanner (Micro MRI, Varian 7T). The tumor-bearing mouse was anesthetized with isoflurane. The mouse was scanned before and after $24 \mathrm{~h}$ intravenous injection of UCNP-PEG-FA/PC 70 nanoparticles $\left(200 \mu \mathrm{l}, 4 \mathrm{mg} \mathrm{ml}^{-1}\right)$.

\section{Histopathological examination}

The tissues (heart, liver, spleen, kidneys and lung) were harvested and fixed in a $4 \%$ formalin solution. The histopathological tests were performed according to standard laboratory procedures. Tissue samples were numbered and given blind to the pathologist for conventional processing and analysis. Briefly, the tissue samples were embedded in paraffin blocks, sectioned into $5 \mu \mathrm{m}$ slices, and mounted onto glass slides. The sections were observed after hematoxylin and eosin staining, and photographs were taken using an optical microscope.

\section{RESULTS AND DISCUSSION}

\section{Synthesis and characterization of UCNP-PEG-FA/PC 70}

$\mathrm{PC}_{70}$ dyad was synthesized according to our previously reported paper. $^{25}$ (Supplementary Scheme S1, step 1). To obtain prominent UV-visible emission, $\mathrm{NaGdF}_{4}: \mathrm{Yb}, \mathrm{Tm} @ \mathrm{NaGdF}_{4}$ core/shell nanoparticles were prepared as the upconversion energy donor. Moreover, $\mathrm{Gd}^{3+}$ ions-based host lattice was employed to support the MRI capability by shortening the relaxtion time of $T_{1}$. The synthesis of the core/shell UCNPs was enabled with a modified thermolysis method (Supplementary Scheme S1, step 2). ${ }^{39,40}$
As given in Supplementary Figure S1a, the core and core/shell UCNPs were sphere-like, with high uniformity in size and morphology. After epitaxial growth of the nanoshells (Figure 2a), the mean particle size increased by $\sim 20 \mathrm{~nm}$. Furthermore, the high-resolution TEM image of core/cell nanoparticles (Figure 2b) exhibited legible lattice fringes of $0.52 \mathrm{~nm}$, indicating the (1010) plane of $\beta-\mathrm{NaGdF}_{4}$, whereas the successful formation of $\beta$-phase UCNPs was also confirmed by the X-ray diffraction patterns (Figure $2 \mathrm{~d}$ ). The upconversion spectra in Supplementary Figure S2 show that the emission intensity of $\mathrm{NaGdF}_{4}: \mathrm{Yb}, \mathrm{Tm} @ \mathrm{NaGdF}_{4}$ core/shell UCNPs enhanced 13 times compared with the $\mathrm{NaGdF}_{4}: \mathrm{Yb}, \mathrm{Tm}$ counterpart, indicating the higher upconversion efficiency of the core/shell UCNPs. Afterward, a ligand exchange strategy was employed to transfer the hydrophobic oleate-capped UCNPs to aqueous solutions, where the oleate ligands were replaced by citric acid molecules. As shown in Supplementary Figure S3, no obvious change in size and morphology of the UCNPs occurred after the ligand exchange process. Meanwhile, the emission intensity of $\mathrm{Tm}^{3+}$ decreased due to the quenching effect induced by the vibration stretching of hydroxyl groups (Supplementary Figure S4).

Subsequently, water-dispersible and carboxyl-functionalized UCNPs were modified by $\mathrm{PC}_{70}$ via electrostatic interactions and then encapsulated by folate-modified polyoxyethylenebis (amine). TEM image shows little change in size of the UCNPs after modification by PEG and $\mathrm{PC}_{70}$ (Figure 2c), which may be caused by light atoms with lower constrast compared with that of heavy atoms. Whereas the dynamic light scattering distribution indicates that the hydrated ionic radius is ca. $186 \mathrm{~nm}$, which may ascribe to the free stretching of PEG (Supplementary Figure S5). Further investigation illustrates that the as-prepared UCNP-PEG-FA/PC 70 nanocomposites are reasonably stable in phosphate-buffered saline, fetal bovine serum and Dulbecco's modified Eagle's medium (Figure 2e), which should mainly attribute to the negative charged property $(-15 \mathrm{mV})$ of UCNP-PEG-FA/PC 70 . The moderate dispersibility facilitates further biomedical applications. The IR spectrum indirectly verifies the formation of amido bond (Supplementary Figure S6). Loading efficiency of $\mathrm{PC}_{70}$ was measured as shown in Supplementary Figure S7a, and the result suggested that the loading efficiency is ca. $20 \%$. Release behavior of $\mathrm{PC}_{70}$ was also evaluated in $10 \%$ fetal bovine serum (Supplementary Figure S7b). $\mathrm{PC}_{70}$ could release from the nanocomposite with an amount of ca. $5-7 \%$ indicating that the multifunctional composite is reasonably stable under physiological conditions.

Figure $2 \mathrm{~g}$ reveals that the absorption spectrum of $\mathrm{PC}_{70}$ overlaps with the UV emission of UCNPs at $290 \mathrm{~nm}\left({ }^{1} \mathrm{I}_{6}-{ }^{3} \mathrm{H}_{6}\right), 345 \mathrm{~nm}$ $\left({ }^{1} \mathrm{I}_{6}-{ }^{3} \mathrm{~F}_{4}\right), 361 \mathrm{~nm}\left({ }^{1} \mathrm{D}_{2}-{ }^{3} \mathrm{H}_{6}\right)$, and the visible emission at $451 \mathrm{~nm}$ $\left({ }^{1} \mathrm{D}_{2}-{ }^{3} \mathrm{~F}_{4}\right), 475 \mathrm{~nm}\left({ }^{1} \mathrm{G}_{4}-{ }^{3} \mathrm{H}_{6}\right)$, indicating that the emissions of UCNPs matched well with the absorption of $\mathrm{PC}_{70}$. Hence, $\mathrm{PC}_{70}$ can be activated by the energy transfer from UCNPs upon NIR irradiation. To further verify the efficient energy transfer from the UCNPs to $\mathrm{PC}_{70}$, the emission spectra of UCNP-PEG-FA nanoparticles incubated with different concentration of $\mathrm{PC}_{70}$ were monitored upon $980 \mathrm{~nm}$ irradiation. As depicted in Figure $2 \mathrm{~h}$, the UV-visible emissions of $\mathrm{Tm}^{3}$ ${ }^{+}$were progressively quenched with elevated addition of $\mathrm{PC}_{70}$, whereas the emission of $\mathrm{Tm}^{3+}$ at $800 \mathrm{~nm}\left({ }^{3} \mathrm{H}_{4}-{ }^{3} \mathrm{H}_{6}\right)$ was almost constant, indicating that the energy transfer indeed occurred between UCNPs and $\mathrm{PC}_{70}$ due to the overlap of emission and absorption spectra in UV-visible range. As a result, a slight red-shift of the UV-visible absorption at $428 \mathrm{~nm}$ (Figure 2f) and an obvious red-shift of the typical FL spectrum of $\mathrm{PC}_{70}$ (Supplementary Figure S8) were observed for UCNP-PEG-FA/PC 70 due to the interaction between UCNPs and $\mathrm{PC}_{70}$. These results indirectly indicate that fluorescence resonance 
a

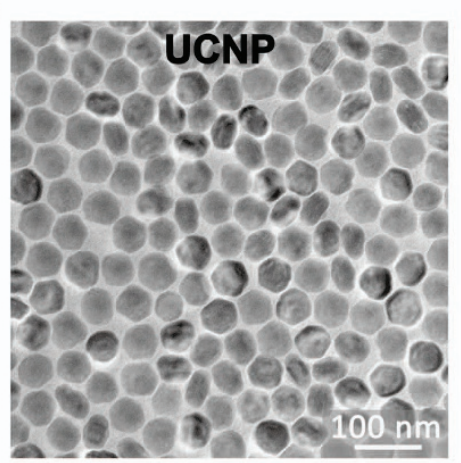

d
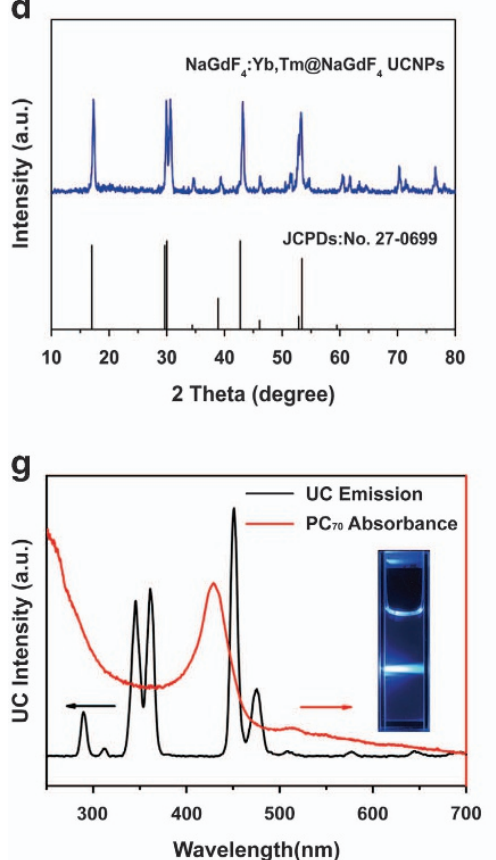

b

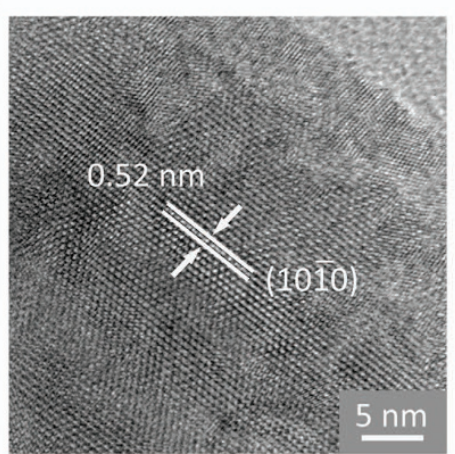

e

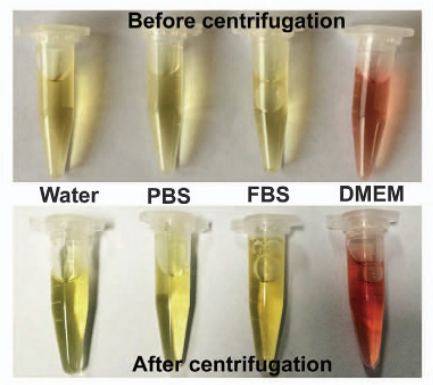

h

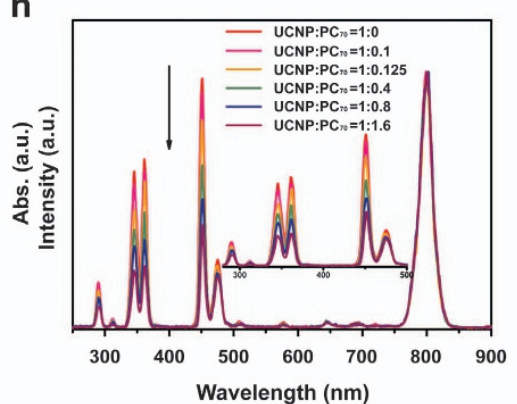

C

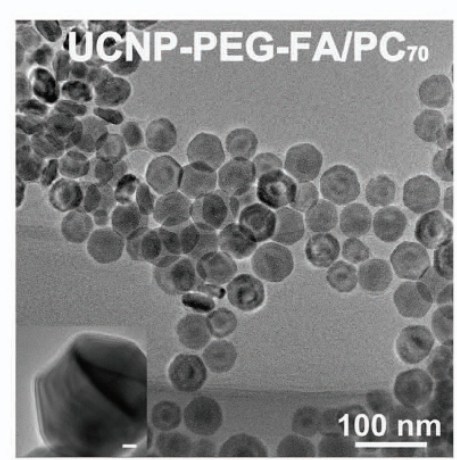

f

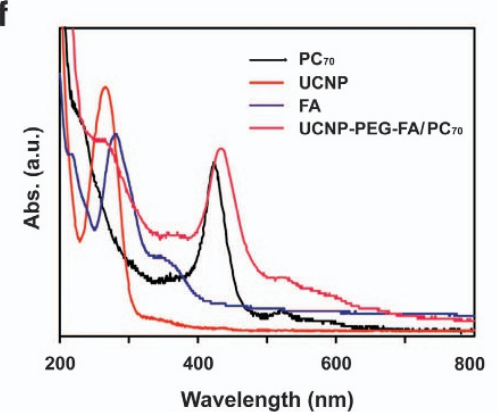

i

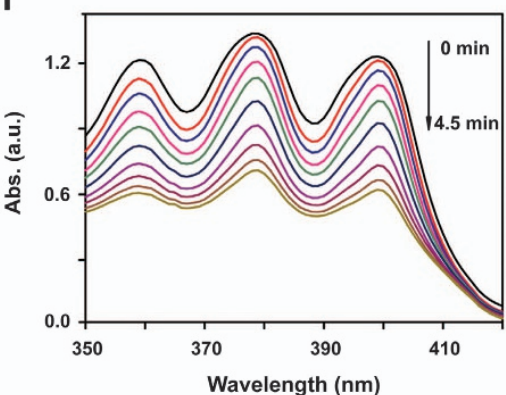

Figure 2 (a) Transmission electron microscope (TEM) image of $\beta-\mathrm{NaGdF}_{4}: \mathrm{Yb}_{2}, \mathrm{Tm}_{\mathrm{N}} @ \mathrm{NaGdF}_{4}$ nanoparticles. (b) High-resolution TEM image of $\beta-\mathrm{NaGdF}$ : $\mathrm{Yb}$, Tm@NaGdF 4 nanoparticle. (c) TEM images of UCNP-PEG-FA/PC 70 (upconversion-nanoparticles-trismethylpyridylporphyrin-fullerene nanocomposite). Inset is enlarged image and the scale bar is $5 \mathrm{~nm}$. (d) X-ray diffraction pattern of as-prepared $\beta-\mathrm{NaGdF}_{4}: \mathrm{Yb}_{\mathrm{T}} \mathrm{Tm}_{\mathrm{N}} \mathrm{NaGdF}{ }_{4}$ nanoparticles, consistent with the standard pattern of $\beta-\mathrm{NaGdF}_{4}$ (JCPDS 06-0342). (e) Optical photographs of UCNP-PEG-FA/PC 70 in water, phosphate-buffered saline, fetal bovine serum and Dulbecco's modified Eagle's medium respectively: before centrifugation (top) and after centrifugation (bottom). (f) Absorption spectra of UCNP-PEG-FA/PC 70 , UCNPs, $\mathrm{FA}$ and $\mathrm{PC}_{70}$. (g) Upconversion emission spectrum of UCNPs and absorption spectrum of $\mathrm{PC}_{70}$. Inset is the digital luminescence photograph of UCNPs. (h) Upconversion emission spectra of UCNP-PEG-FA solutions treated with $\mathrm{PC}_{70}$ at different concentrations upon $980 \mathrm{~nm}$ irradiation (excitation power was $4 \mathrm{~W} \mathrm{~cm}^{-2}$ ). The concentrations of UCNPs in samples are identical. Inset is a local amplification profile of spectra. (i) Photodegradation of $\mathrm{Na}_{2}$-ADPA treated with UCNP-PEG-FA/PC 70 at different time points due to generation of singlet oxygen upon $980 \mathrm{~nm}$ irradiation.

energy transfer may exist between UCNPs and $\mathrm{PC}_{70}$. Subsequently, the feasibility of UCNP-PEG-FA/PC 70 for producing ${ }^{1} \mathrm{O}_{2}$ was investigated by using chemical trapping method (Figure 2i). The result indicates that the photodegradation of $\mathrm{Na}_{2}-\mathrm{ADPA}$ is time-dependent once treated with UCNP-PEG-FA/PC 70 and $980 \mathrm{~nm}$ irradiation. All of these results indicate that the as-synthesized UCNP-PEG-FA/PC 70 nanocomposites not only exhibit reasonable stability under physiological conditions but also efficiently produce singlet oxygen upon $980 \mathrm{~nm}$ irradiation.

\section{The photodynamic activity in vitro}

To investigate the NIR light-triggered PDT effect of UCNP-PEG-FA/ $\mathrm{PC}_{70}$, the in vitro viability assay of Hela-luc cells was performed under normal conditions and $\mathrm{N}_{2}$-puring conditions (simulate a low oxygen condition) as a model. As given in Figure $3 \mathrm{a}$, the cell viabilities decrease gradually with the increase of nanoparticles from 0 to 200 $\mu \mathrm{g} \mathrm{ml}^{-1}$ upon $980 \mathrm{~nm}$ laser irradiation at a power density of 0.8 $\mathrm{W} \mathrm{cm}{ }^{-2}\left(480 \mathrm{~J} \mathrm{~cm}^{-2}\right.$, lower than that of previously reported: 4.5 $\left.\mathrm{W} \mathrm{cm}{ }^{-2}, 10800 \mathrm{~J} \mathrm{~cm}^{-2}\right),{ }^{8}$ and $90 \%$ inhibitory effect on the cell viability was detected at $0.15 \mathrm{mg} \mathrm{ml}^{-1}$ of UCNP-PEG-FA/PC 70 . Meanwhile, negligible cytotoxicity against the Hela-luc cell was observed in the dark, indicating the favorable biocompatibility of UCNP-PEG-FA/PC 70 nanocomposites. The same experiments were done under the $\mathrm{N}_{2}$-puring conditions. As shown in Figure $3 \mathrm{~b}$, the cell viabilities decrease gradually with the increase of UCNP-PEG-FA/ $\mathrm{PC}_{70}$ from 0 to $200 \mu \mathrm{g} \mathrm{ml}^{-1}$ under $\mathrm{N}_{2}$-puring condition, and $50 \%$ inhibitory effect on the cell viability was detected at $0.2 \mathrm{mg} \mathrm{ml}^{-1}$. The results indicate that UCNP-PEG-FA/PC ${ }_{70}$ can produce ${ }^{1} \mathrm{O}_{2}$ under 

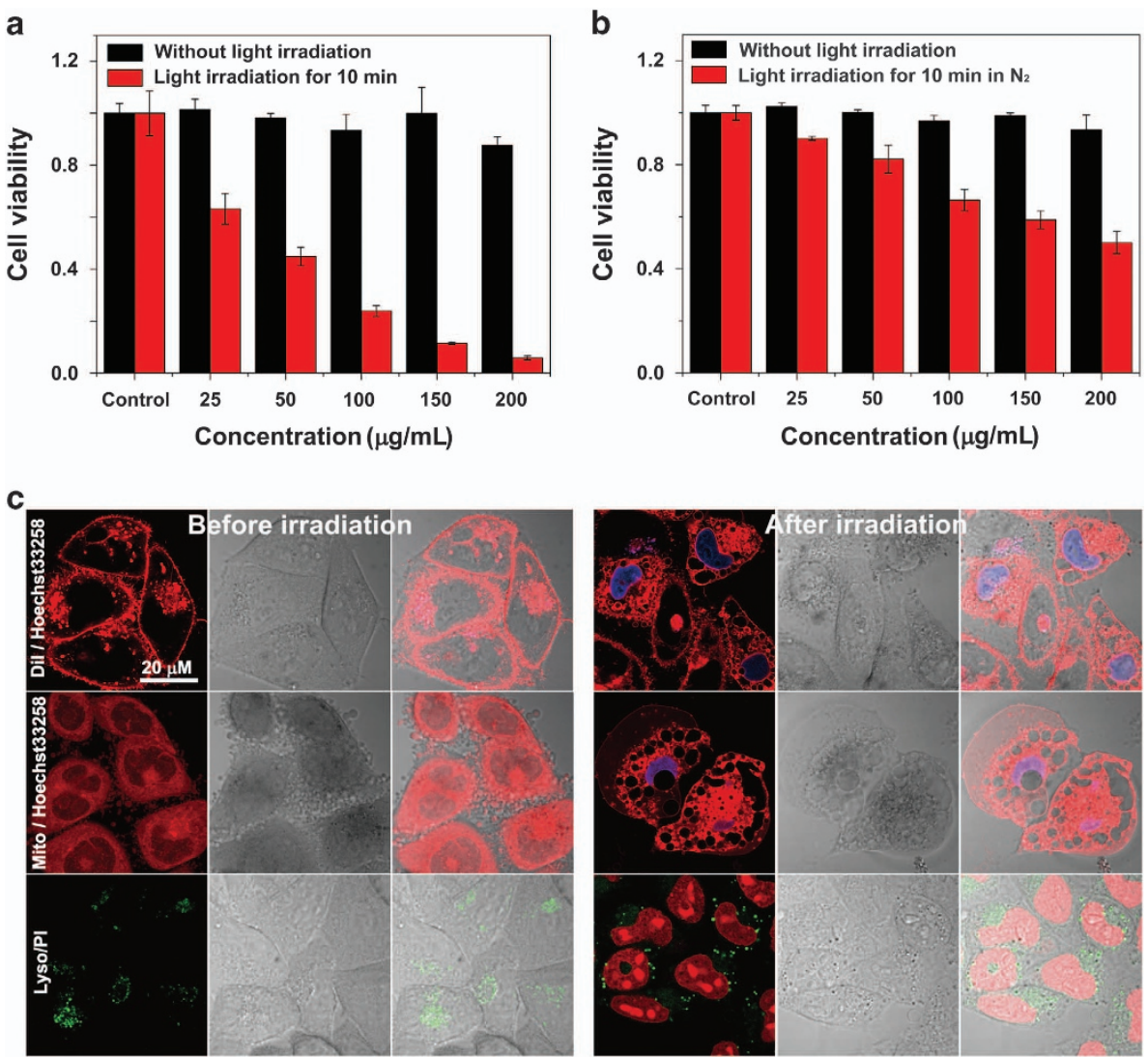

Figure 3 (a) In vitro relative viabilities of Hela-/uc cells incubated with UCNP-PEG-FA/PC 70 (upconversion-nanoparticles-trismethylpyridylporphyrin-fullerene nanocomposite) at different concentrations, with (red) and without (black) $980 \mathrm{~nm}$ NIR light irradiation. (b) Relative viabilities of Hela-/uc cells under nitrogen-purging conditions incubated with UCNP-PEG-FA/PC 70 at different concentrations, with (red) and without (black) $980 \mathrm{~nm}$ NIR light irradiation. (c) Confocal images before (left) and after (right) NIR light irradiation. First line was stained with Dil and Hoechst 33258 , second line was stained with MitoRed and Hoechst 33258, third line was stained with PI and Lyso. Each group with three columns represent fluorescence image, optical image and merged image, respectively, from left to right.

low-oxygen conditions, which may be attributable to the formation of $\left({ }^{3} \mathrm{PC}_{70}\right)^{*}$ with a long triplet lifetime state and thus have enough time to interact with free oxygen. ${ }^{38}$

Several subcellular organelles were stained by related probes and observed under confocal microscope to confirm that the cells were destructed after incubation with UCNP-PEG-FA/PC 70 and subsequent irradiation with 980-nm NIR light. As shown in Figure 3c, the images in the first row were stained by Dil (cell membrane dye) and Hoechst 33258 (nucleus dye), from which we can see clearly that the cell membrane was bubbling and the nucleus was stained in blue after 980-nm irradiation, indicating that the cell membrane was destroyed and the cells died. The second row was stained by MitoRed tracker (mitochondrial dye) and Hoechst 33258, and the third row was stained by Lyso tracker (lysosome dye) and PI (nucleus dye). The compact mitochondria and lysosomes become incomplete after irradiation, indicating that the subcellular organelles were destroyed by ${ }^{1} \mathrm{O}_{2}$ generated from UCNP-PEG-FA/PC 70 after $980 \mathrm{~nm}$ irradiation. The lightened subcellular organelles indirectly illustrated that the nanocomposites were internalized into cells and produced intracellular ROS to destroy the subcellular organelles when exposed to NIR light irradiation.

Improved photodynamic activity by conjugation with folate To reduce the photodynamic damage of synthesized nanoparticles to normal cells and enhance the PDT efficiency toward tumor cells, folate-modified UCNP-PEG-FA/PC 70 was designed. As shown in Figure 4a, UCNP-PEG-FA/PC 70 hybrid exhibits a dramatic decrease in cell viability even at low concentration of $0.2 \mathrm{mg} \mathrm{ml}^{-1}$, whereas UCNPs or $\mathrm{PC}_{70}$ alone showed a negligible effect under the same conditions. Moreover, A549 and HBE cells with negative expression of folate receptor were used as controls to evaluate the PDT efficiency. The results indicate that all the above materials including UCNPPEG-FA/PC 70 show negligible cytotoxicity toward A549 and HBE cells, suggesting that the superior PDT effect should benefit from the higher binding affinity of the folate-modified nanoprobe to folate receptor overexpressed Hela-luc cells.

Competitive inhibition experiment was carried out to further confirm the targeting specificity of UCNP-PEG-FA/PC 70 . UCNP$\mathrm{PEG} / \mathrm{PC}_{70}$ (without folate) and UCNP-PEG-FA/PC 70 blocking with an excess of folate during the incubation were used in PDT treatment as controls. As shown in Figure 4a, UCNP-PEG/PC 70 exhibited negligible effect on the above three kinds of cells, suggesting that UCNP-PEG/PC 70 fails to effectively attach to the cell surface at absence of folate. Moreover, the blocking group of UCNP-PEG-FA/ $\mathrm{PC}_{70}$ reveals that the existence of free folate could inhibit the affinity of UCNP-PEG-FA/PC 70 to Hela-luc cells and therefore effectively preserve the cells from PDT damage (Figure 4b). In addition, confocal imaging experiment was explored to further confirm the above results. Strong red fluorescence could be observed when the Hela-luc cells 
a

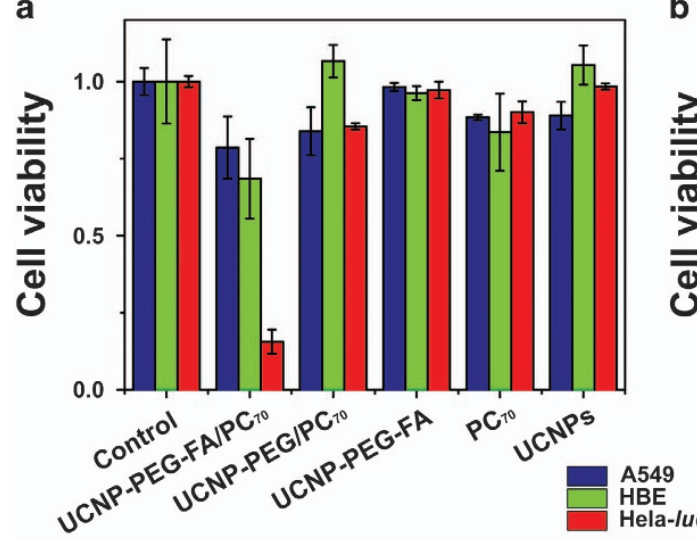

b

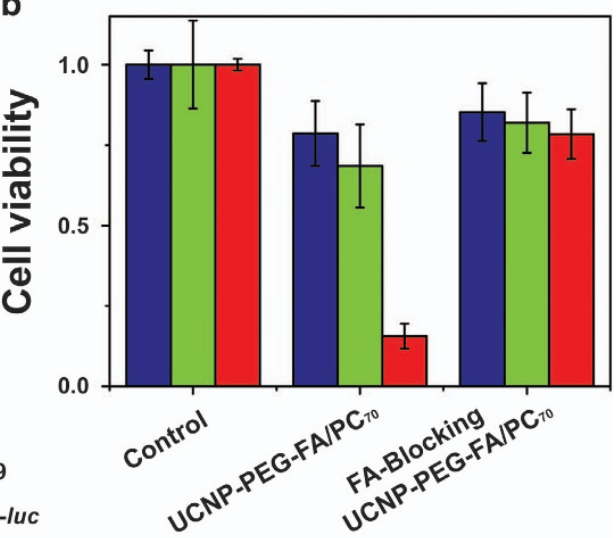

C
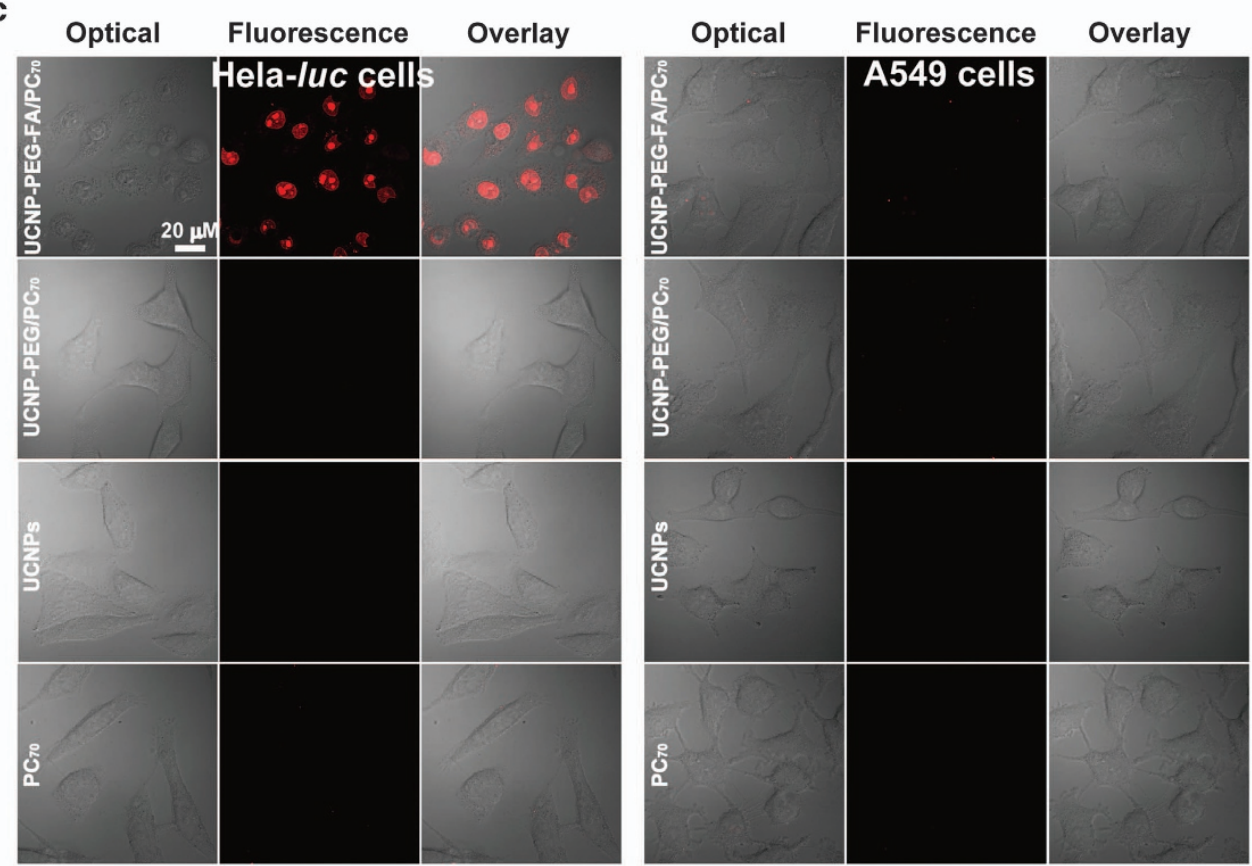

Figure 4 (a) The viabilities of three kinds of cells (Hela-/uc, A549 and HBE cells) incubated with UCNP-PEG-FA/PC 70 (upconversion-nanoparticlestrismethylpyridylporphyrin-fullerene nanocomposite), UCNP-PEG/PC 70 , UCNP-PEG-FA, PC 70 and UCNPs respectively. (b) The viabilities of three kinds of cells (Hela-Iuc, A549 and HBE cells) incubated with either UCNP-PEG-FA/PC 70 or the mixture of UCNP-PEG-FA/PC 70 and an excess of folate. (c) Confocal images of PI stained Hela-/uc cells (left) and A549 cells (right) after photodynamic therapy treatment with UCNP-PEG-FA/PC 70, UCNP-PEG/PC 70, UCNP and $\mathrm{PC}_{70}$ from top to bottom, respectively.

were treated with UCNP-PEG-FA/PC 70 and subsequently exposed to 980-nm irradiation and stained by PI. Meanwhile, controls groups (UCNP-PEG-FA/PC $70^{-}$treated A549 cells and UCNP-PEG/PC $70^{-}$, UCNPs- and $\mathrm{PC}_{70}$-treated $\mathrm{A} 549$ cells, as well as $\mathrm{HBE}$ cells and Hela-luc cells) exhibited negligible fluorescence under the same conditions (Figure 4c). These results highlight the targeting capability and specificity of UCNP-PEG-FA/PC 70 nanocomposites toward Hela$l u c$ cells via the recognition between folate and folate receptor on the Hela-luc cell surface.

\section{Fluorescence/UCL/MR/trimodal imaging}

Despite the promising results obtained in vitro, one of the most demanding challenges regarding multifunctional platforms still lies in good sensitivity in vivo and real-time monitoring for optimized treatment. Herein, the fluorescence intensity in vivo was detected to evaluate the real-time biodistribution of UCNP-PEG-FA/PC 70 nanoparticles. For in vivo optical imaging studies, tumor-bearing nude mice were injected with UCNP-PEG-FA/PC 70 through the tail vein $\left(20 \mathrm{mg} \mathrm{kg}^{-1}\right)$. The resulting fluorescence avoids the autofluorescence from biological tissues and could be used to image the specifics sensitively in vivo. From the chronological observation of the images in Figure $5 \mathrm{a}$, we detected the appearance of a rapid tropism associated with the biodistribution of UCNP-PEG-FA/PC 70 nanoparticles. The fluorescence intensity of UCNP-PEG-FA/PC 70 in tumor increases to the maximum after $24 \mathrm{~h}$ post injection and then decreases with the prolonging time. At the time point of $24 \mathrm{~h}$, the tumor and other organs of the nude mouse injected with UCNP-PEG-FA/PC 70 were harvested for ex vivo imaging to quantify tissue/organ distribution (Figure 5b). The result revealed that distinct fluorescence was presented in tumor site and also in the liver and kidney. By contrast, as given in Supplementary Figure S9, the mouse treated with UCNP$\mathrm{PEG} / \mathrm{PC}_{70}$ showed negligible fluorescence after $4 \mathrm{~h}$ post-injection. The 

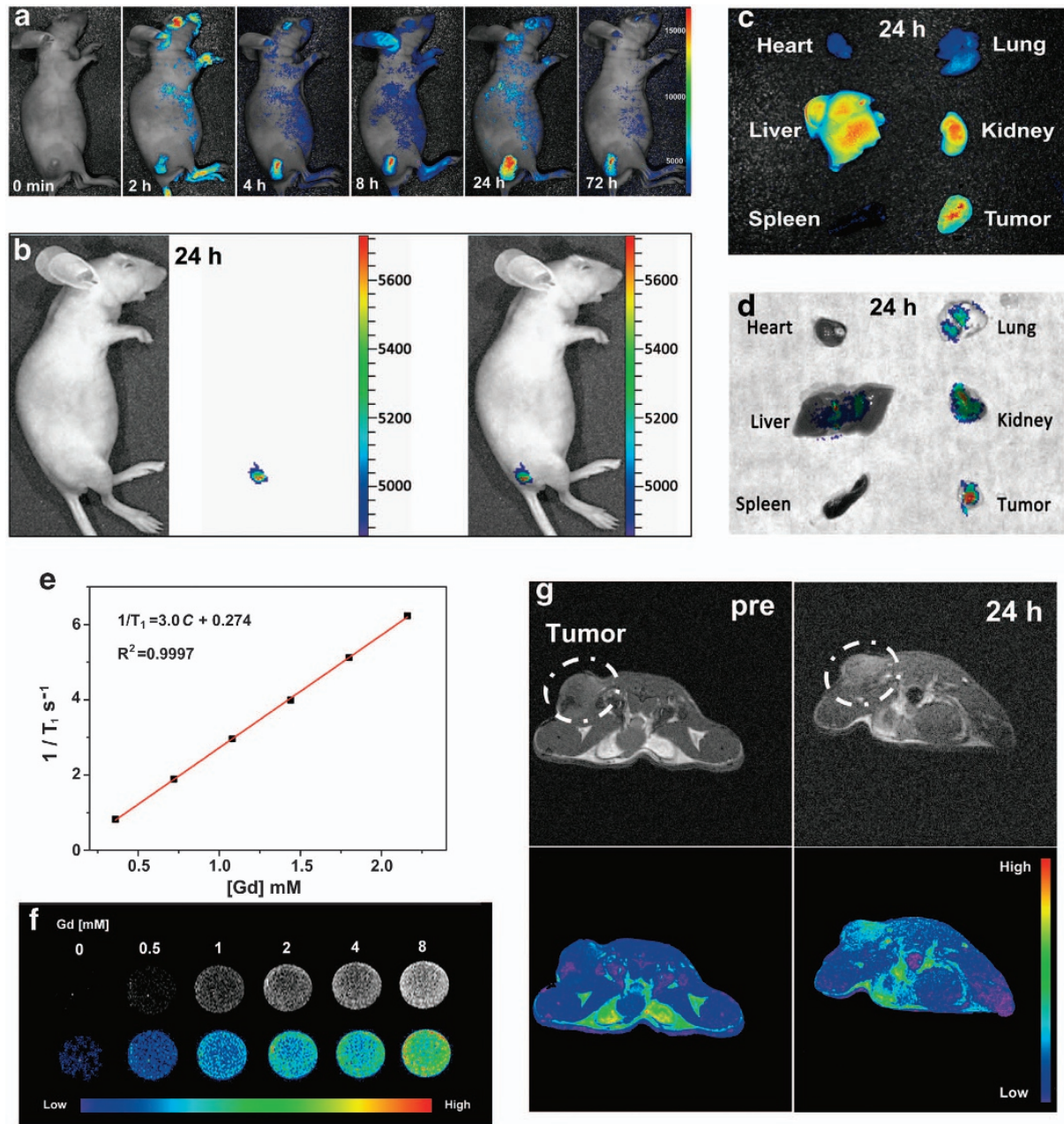

Figure 5 (a) In vivo fluorescence images of a tumor-bearing mouse at different time points after treatment with UCNP-PEG-FA/PC 70 (upconversionnanoparticles-trismethylpyridylporphyrin-fullerene nanocomposite). (b) UCL images at the time point of $24 \mathrm{~h}$, and images from left to right represent optical image, UCL image, and merged image. Ex vivo images of tumor and other organs after $24 \mathrm{~h}$ post-injection: (c) fluorescence image and (d) UCL image. (e) Relaxation rate $R_{1}$ versus different molar concentrations of UCNP-PEG-FA/PC 70 nanoparticles. (f) In vitro $T_{1}$-weighted MR images of UCNP-PEG-FA/PC 70 at different Gd concentrations. (g) In vivo $T_{1}$-weighted MR image of a tumor-bearing nude mouse: preinjection (left) and after 24-h post injection (right). The color images are treated by pseudo-color.

ex vivo imaging obtained after $24 \mathrm{~h}$ post injection (Supplementary Figure S10) indicated the maximal accumulation in the liver and kidney and only a weak fringe of fluorescence located in tumor sites. These results demonstrate that the active targeting of folic and enhanced permeability and retention effect mediated passive targeting play a synergistic role for the accumulation of UCNP-PEG-FA/PC 70 nanocomposites in tumor. Most interestingly, the real-time fluorescence images not only confirm the feasibility of fluorescence-guided PDT but also contribute to the enhanced efficiency of PDT.

In addition, the emission of UCNPs at $800 \mathrm{~nm}$ could be used as the output signal to realize the NIR-to-NIR UCL imaging. The images from left to right in Figure $5 \mathrm{c}$ represent the optical image of mouse, UCL image, and their merged images at $24 \mathrm{~h}$ post injection, which depict the tumor clearly. The ex vivo UCL imaging (Figure 5d) further indicated that UCNP-PEG-FA/PC 70 mainly accumulated in the liver, spleen and tumor, which were similar to the result from fluorescence image.

To demonstrate the MRI capability of UCNP-PEG-FA/PC $70, T_{1}$ relaxation time and $T_{1}$-weighted $\mathrm{MR}$ images at different Gd concentrations were obtained with a $0.5 \mathrm{~T}$ MRI scanner. The measured $r_{1}$ value was ca. $3.0 \mathrm{mM}^{-1} \mathrm{~s}^{-1}$ for UCNP-PEG-FA/PC 70 nanocomposites (Figure 5e), which was comparable to that of clinically used Gd-DTPA (3-4 $\left.\mathrm{mM}^{-1} \mathrm{~s}^{-1}\right)$ under the same conditions. $T_{1}$-weighted MR images (Figure 5f) enhanced with the increase of Gd concentration from 0 to $8 \mathrm{mM}$. For better visual effect, pseudocolor image was used to enhance the sensitivity. In vivo MR imaging was performed for a tumor-bearing mouse with a $7 \mathrm{~T}$ MR scanner (Figure $5 \mathrm{~g}$ ). The tumor site was clearly depicted after 24-h post injection, indicating that UCNP-PEG-FA/ $\mathrm{PC}_{70}$ can be used as a potential $T_{1} \mathrm{MRI}$ contrast agent. The results from MR image are reasonably consistent with those from fluorescence and UCL images, which also indicate the better tumor targeting performance of UCNP-PEG-FA/PC 70 as an entity. In a word, the obtained results indicate that UCNP-PEG-FA/PC 70 could be employed as an efficient and trimodal FL/UCL/MR imaging agent in vivo and direct the optimized PDT treatment.

\section{In vivo $\mathrm{PDT}$}

The PDT experiments were conducted in vivo to evaluate the tumor inhibition efficacy of the UCNP-PEG-FA/PC 70 with $980 \mathrm{~nm}$ NIR light irradiation. The luciferase-expressing cervical cancer cell line Hela-luc 

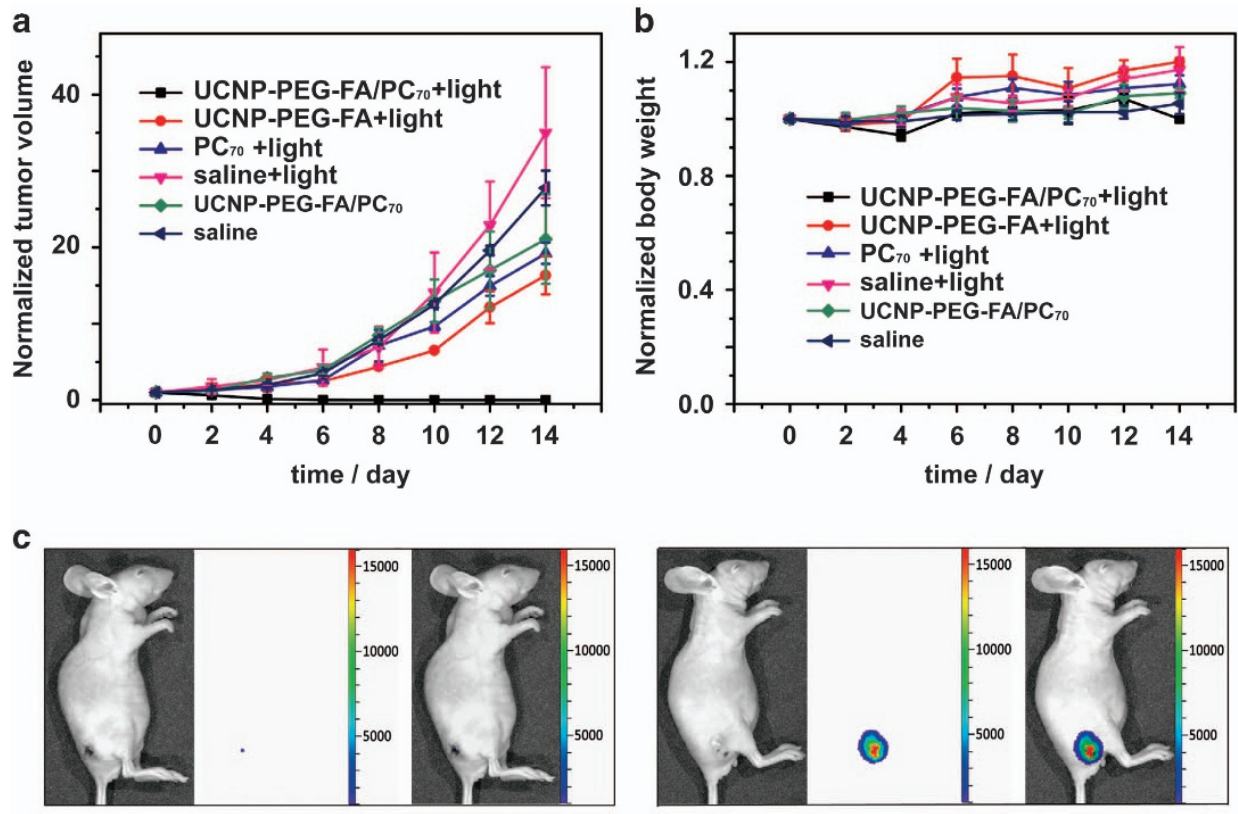

d
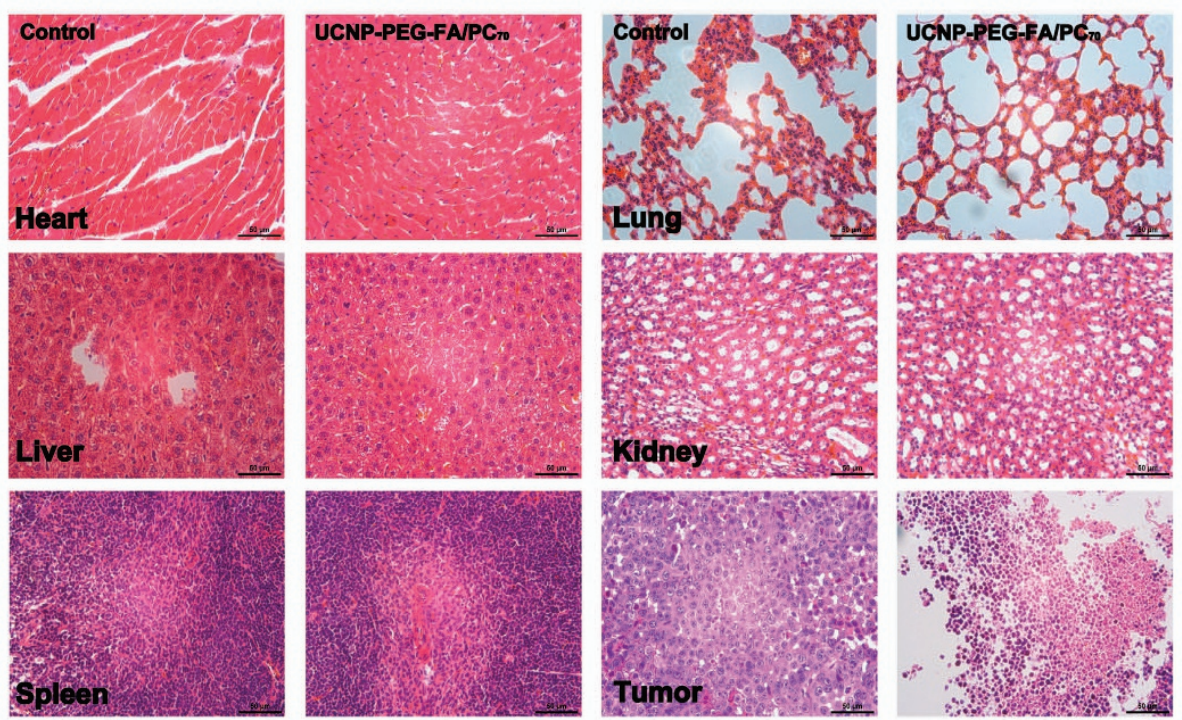

Figure 6 (a) Growth of tumors after treatments. The relative tumor volumes were normalized to their initial sizes. (b) The relative body weights of the nude mice increased continuously after different treatments. Error bars indicate standard deviations; $n=3$. (c) Bioluminescence images of different treatments after 14 days: UCNP-PEG-FA/PC $70+980 \mathrm{~nm}$ NIR light irradiation (left) and saline+980 NIR light irradiation (right). (d) Hematoxylin and eosin stained images of tumors and other organs under different photodynamic therapy treatments.

was selected as the xenograft model, and tumor-bearing nude mice were randomly divided into six groups $(n=3)$. The first group was irradiated with $980 \mathrm{~nm}$ NIR light $\left(0.7 \mathrm{~W} \mathrm{~cm}^{-2}, 126 \mathrm{~J} \mathrm{~cm}^{-2}, 30 \mathrm{~s}\right.$ break after $30 \mathrm{~s}$ irradiation) in the tumor site for $3 \mathrm{~min}$ (lower than that of previously reported: $\left.2.5 \mathrm{~W} \mathrm{~cm}^{-2}, 30 \mathrm{~min}, 4500 \mathrm{~J} \mathrm{~cm}^{-2}\right)^{8}$ after injection with UCNP-PEG-FA/PC $70\left(2 \mathrm{mg} \mathrm{ml}^{-1}, 200 \mu \mathrm{l}\right)$ for $24 \mathrm{~h}$ through caudal vein. In addition, short-interval irradiation method was developed to avoid over-heating by the NIR light. The next three groups were injected with UCNP-PEG-FA, $\mathrm{PC}_{70}$, and saline, respectively, and then irradiated under the same conditions as controls. Another two groups injected with either UCNP-PEG-FA/PC 70 or saline separately without irradiation were used as controls. Figure $6 \mathrm{a}$ demonstrates that the group treated with UCNP-PEG-FA/PC $70^{+}$ $980 \mathrm{~nm}$ NIR light irradiation exhibited optimal tumor growth inhibition efficacy. By contrast, the tumors of control groups grew continuously under the same conditions. Meanwhile, the digital photographs of representative mice with neoplasm (Supplementary Figure S11) before and after irradiation for 6 days showed that the tumor sizes of mice treated with UCNP-PEG-FA/PC $70+980 \mathrm{~nm}$ NIR light irradiation were much smaller than those of control groups, as confirmed by the representative bioluminescence images of mice (Supplementary Figure S12) given at the 14th day (Figure 6c). Bioluminescence from the UCNP-PEG-FA/PC $70+980 \mathrm{~nm}$ NIR light irradiation-treated group nearly disappeared compared with salinetreated mice, suggesting that the tumor of treated group was effectively destroyed. Hematoxylin and eosin staining images of main organs and tumor are presented in Figure 6d. The clear separation of the nuclear and cytoplasm confirmed that the tumor cells were destroyed after 
treated with UCNP-PEG-FA/PC $70+980 \mathrm{~nm}$ NIR light irradiation. By contrast, tumor from the mouse treated with saline exhibited cramped construction of nuclear and cytoplasm. Importantly, there were no obvious lesions were found in other organs, indicating that UCNPPEG-FA/PC 70 has no significant toxicity to organisms. In addition, body weight, as an important parameter to evaluate the systemic toxicity of nanomaterials, did not show abnormal change for all groups (Figure $6 \mathrm{~b}$ ), indicating that UCNP-PEG-FA/PC 70 nanocomposite does not have obvious adverse side effects.

\section{CONCLUSION}

In summary, we have successfully prepared UCNP-PEG-FA/PC 70 nanocomposite as an NIR light-triggered and targeted theranostic platform for trimodal imaging-guided PDT in vitro as well as in vivo. The developed UCNP-PEG-FA/PC 70 nanocomposites have the following advantages: (1) Upon NIR irradiation, UCNPs could convert NIR light into UV-to-visible light to effectively activate $\mathrm{PC}_{70}$ to produce ${ }^{1} \mathrm{O}_{2}$ for killing tumor under low oxygen conditions; (2) Three kinds of imaging methods (FL/UCL/MR) were integrated into one system to provide the complementary information for accurate diagnosis and guide treatment of tumor; (3) Folate-mediated active targeting together with the PEG leaded enhanced permeability and retention effect effect (passive targeting) enhances the accumulation of multifunctional nanoparticles in tumor. Importantly, the synthesized UCNP-PEG-FA/PC 70 may provide solutions to the two bottleneck problems of PDT, namely, limited penetration depth and oxygendeficient microenvironment. These results highlight the potential of UCNP-PEG-FA/PC 70 as a multifunctional theranostic agent for imaging-guided PDT of tumor and a promising candidate for overcoming the problem of existing PDT agents in deep cancerous tissue under hypoxic conditions.

\section{CONFLICT OF INTEREST}

The authors declare no conflict of interest.

\section{ACKNOWLEDGEMENTS}

This work is supported by 973 Program (No. 2011CB302100), the Ministry of science and technology support program (No. 2011BAK15B04), the Chinese Academy of Sciences (No. XDA09030302), the National Natural Science Foundation of China (Nos. 51372251, 51472252) and the Key Research Program of the Chinese Academy of Sciences (Grant no. KGZDEW-T02).

Author contributions: CS and JG planned and supervised the project. MG carried out the detailed experiments. MG, JG and CS analyzed the data and wrote the whole paper. HD contributed to the synthesis and characterization of UCNPs and helped the analysis of the data. DC, LS, CY, CW and PW contributed to discussion of the paper.

$1 \mathrm{He}, \mathrm{Q}$. \& Shi, J. MSN anti-cancer nanomedicines: chemotherapy enhancement, overcoming of drug resistance, and metastasis inhibition. Adv. Mater. 26, 391-411 (2014).

2 Chen, X., Gambhir, S. S. \& Cheon, J. Theranostic nanomedicine. Acc. Chem. Res. 44, 841 (2011).

3 Wang, J., Hu, Z., Xu, J. \& Zhao, Y. Therapeutic applications of low-toxicity spherical nanocarbon materials. NPG Asia Mater. 6, e84 (2014).

4 Tian, B., Wang, C., Zhang, S., Feng, L. \& Liu, Z. Photothermally enhanced photodynamic therapy delivered by nano-graphene oxide. ACS Nano $\mathbf{5}$, 7000-7009 (2011).

5 Ge, J., Lan, M., Zhou, B., Liu, W., Guo, L., Wang, H., Jia, Q., Niu, G., Huang, X., Zhou, H., Meng, X., Wang, P., Lee, C. S., Zhang, W. \& Han, X. A graphene quantum dot photodynamic therapy agent with high singlet oxygen generation. Nat. Commun. $\mathbf{5}$ 4596-4603 (2014).

6 Chen, D., Wang, C., Nie, X., Li, S., Li, R., Guan, M., Liu, Z., Chen, C., Wang, C., Shu, C. \& Wan, L. Photoacoustic imaging guided near-infrared photothermal therapy using highly water-dispersible single-walled carbon nanohorns as theranostic agents. Adv. Funct. Mater. 24, 6621-6628 (2014).

7 Liang, C., Diao, S., Wang, C., Gong, H., Liu, T., Hong, G., Shi, X., Dai, H. \& Liu, Z. Tumor metastasis inhibition by imaging-guided photothermal therapy with single-walled carbon nanotubes. Adv. Mater. 26, 5646-5652 (2014).

8 Dai, Y., Xiao, H., Liu, J., Yuan, Q., Ma, P., Yang, D., Li, C., Cheng, Z., Hou, Z., Yang, P. \& Lin, J. In vivo multimodality imaging and cancer therapy by near-infrared lighttriggered trans-platinum pro-drug-conjugated upconverison nanoparticles. J. Am. Chem. Soc. 135, 18920-18929 (2013).

9 Zhu, H., Chen, H., Zeng, X., Wang, Z., Zhang, X., Wu, Y., Gao, Y., Zhang, J., Liu, K., Liu, R., Cai, L., Mei, L. \& Feng, S. S. Co-delivery of chemotherapeutic drugs with vitamin E TPGS by porous PLGA nanoparticles for enhanced chemotherapy against multi-drug resistance. Biomaterials 35, 2391-2400 (2014).

10 Shieh, M. J., Peng, C. L., Lou, P. J., Chiu, C. H., Tsai, T. Y., Hsu, C. Y., Yeh, C. Y. \& Lai, P. S. Non-toxic phototriggered gene transfection by PAMAM-porphyrin conjugates. J. Control Release 129, 200-206 (2008).

11 Yuan, H., Chong, H., Wang, B., Zhu, C., Liu, L., Yang, Q., Lv, F. \& Wang, S. Chemica molecule-induced light-activated system for anticancer and antifungal activities. J. Am Chem. Soc. 134, 13184-13187 (2012).

12 Li, J., Cai, P., Shalviri, A., Henderson, J. T., He, C., Foltz, W. D., Prasad, P. Brodersen, P. M., Chen, Y., DaCosta, R., Rauth, A. M. \& Wu, X. Y. A multifunctional polymeric nanotheranostic system delivers doxorubicin and imaging agents across the blood-brain barrier targeting brain metastases of breast cancer. ACS Nano 8, 9925-9940 (2014).

13 Huang, P., Wang, D., Su, Y., Huang, W., Zhou, Y., Cui, D., Zhu, X. \& Yan, D. Combination of small molecule prodrug and nanodrug delivery: amphiphilic drug-drug conjugate for cancer therapy. J. Am. Chem. Soc. 136 11748-11756 (2014).

14 Zhang, L., Gao, S., Zhang, F., Yang, K., Ma, Q. \& Zhu, L. Activatable hyaluronic acid nanoparticle as a theranostic agent for optical/photoacoustic image-guided photothermal therapy. ACS Nano 8, 12250-12258 (2014).

15 Fan, Q., Cheng, K., Yang, Z., Zhang, R., Yang, M., Hu, X., Ma, X., Bu, L., Lu, X., Xiong, X., Huang, W., Zhao, H. \& Cheng, Z. Perylene-diimide-based nanoparticles as highly efficient photoacoustic agents for deep brain tumor imaging in living mice. Adv Mater. 27, 843-847 (2015).

16 Vijayaraghavan, P., Liu, C. H., Vankayala, R., Chiang, C. S. \& Hwang, K. C. Designing multi-branched gold nanoechinus for NIR light activated dual modal photodynamic and photothermal therapy in the second biological window. Adv. Mater. 26, 6689-6695 (2014).

17 Yuan, H., Wilson, C. M., Xia, J., Doyle, S. L., Li, S., Fales, A. M., Liu, Y., Ozaki, E., Mulfaul, K., Hanna, G., Palmer, G. M., Wang, L. V. \& Vo-Dinh, T. Plasmonics-enhanced and optically modulated delivery of gold nanostars into brain tumor. Nanoscale 6 , 4078-4082 (2014)

18 Huang, P., Rong, P., Lin, J., Li, W., Yan, X., Zhang, M. G., Nie, L., Niu, G., Lu, J., Wang, W. \& Chen, $X$ Triphase interface synthesis of plasmonic gold bellflowers as nearinfrared light mediated acoustic and thermal theranostics. J. Am. Chem. Soc. 136, $8307-8313$ (2014).

19 Wang, B., Wang, J. H., Liu, Q., Huang, H., Chen, M., Li, K., Li, C., Yu, X. F. \& Chu, P. K. Rose-bengal-conjugated gold nanorods for in vivo photodynamic and photothermal oral cancer therapies. Biomaterials 35, 1954-1966 (2014).

20 Wang, Y., Wang, H., Liu, D., Song, S., Wang, X. \& Zhang, H. Graphene oxide covalently grafted upconversion nanoparticles for combined NIR mediated imaging and photothermal/photodynamic cancer therapy. Biomaterials 34 7715-7724 (2013)

21 Wang, L., Shi, J., Liu, R., Liu, Y., Zhang, J., Yu, X., Gao, J., Zhang, C. \& Zhang, Z. Photodynamic effect of functionalized single-walled carbon nanotubes: a potential sensitizer for photodynamic therapy. Nanoscale 6, 4642-4651 (2014).

22 Kalluru, P., Vankayala, R., Chiang, C. \& Hwang, K. C. Photosensitization of singlet oxygen and in vivo photodynamic therapeutic effects mediated by PEGylated W(18)0 (49) nanowires. Angew. Chem. Int. Ed. 52, 12332-12336 (2013).

23 Cheng, L., Liu, J., Gu, X., Gong, H., Shi, X., Liu, T., Wang, C., Wang, X., Liu, G., Xing, H., Bu, W., Sun, B. \& Liu, Z. PEGylated WS(2) nanosheets as a multifunctional theranostic agent for in vivo dual-modal CT/photoacoustic imaging guided photothermal therapy. Adv. Mater. 26, 1886-1893 (2014).

24 Secret, E., Maynadier, M., Gallud, A., Chaix, A., Bouffard, E., Gary-Bobo, M., Marcotte, N., Mongin, O., Cheikh, K., El, Hugues, V., Auffan, M., Frochot, C. Morere, A., Maillard, P., Blanchard-Desce, M., Sailor, M. J., Garcia, M., Durand, J. O. \& Cunin, F. Two-photon excitation of porphyrin-functionalized porous silicon nanoparticles for photodynamic therapy. Adv. Mater. 26, 7643-7648 (2014).

25 Barreto, J. A., O'Malley, W., Kubeil, M., Graham, B., Stephan, H. \& Spiccia, L. Nanomaterials: applications in cancer imaging and therapy. Adv. Mater. 23, H18-H40 (2011).

26 Maji, S. K., Sreejith, S., Joseph, J., Lin, M., He, T., Tong, Y., Sun, H., Yu, S. W. \& Zhao, Y. Upconversion nanoparticles as a contrast agent for photoacoustic imaging in live mice. Adv. Mater. 26, 5633-5638 (2014).

27 Wang, F., Deng, R., Wang, J., Wang, Q., Han, Y., Zhu, H., Chen, X. \& Liu, X. Tuning upconversion through energy migration in core-shell nanoparticles. Nat. Mater. 10 968-973 (2011).

28 Sun, L. D., Wang, Y. F. \& Yan, C. H. Paradigms and challenges for bioapplication of rare earth upconversion luminescent nanoparticles: small size and tunable emission excitation spectra. Acc. Chem. Res. 47, 1001-1009 (2014). 
29 Li, L. L., Zhang, R., Yin, L., Zheng, K., Qin, W., Selvin, P. R. \& Lu, Y. Biomimetic surface engineering of lanthanide-doped upconversion nanoparticles as versatile bioprobes. Angew. Chem. Int. Ed. Engl. 51, 6121-6125 (2012).

30 Feng, W., Zhu, X. \& Li, F. Recent advances in the optimization and functionalization of upconversion nanomaterials for in vivo bioapplications. NPG Asia Mater. 5, e84 (2013).

31 Qiao, X. F., Zhou, J. C., Xiao, J. W., Wang, Y. F., Sun, L. D. \& Yan, C. H. Triplefunctional core-shell structured upconversion luminescent nanoparticles covalently grafted with photosensitizer for luminescent, magnetic resonance imaging and photodynamic therapy in vitro. Nanoscale 4, 4611-4623 (2012).

32 Zhang, P., Steelant, W., Kumar, M. \& Scholfield, M. Versatile photosensitizers for photodynamic therapy at infrared excitation. J. Am. Chem. Soc. 129, 4526-4527 (2007).

33 Park, Y. I., Kim, H. M., Kim, J. H., Moon, K. C., Yoo, B., Lee, K. T., Lee, N., Choi, Y., Park, W., Ling, D., Na, K., Moon, W. K., Choi, S. H., Park, H. S., Yoon, S. Y., Suh, Y. D., Lee, S. H. \& Hyeon, T. Theranostic probe based on lanthanide-doped nanoparticles for simultaneous in vivo dual-modal imaging and photodynamic therapy. Adv. Mater. 24, 5755-5761 (2012).

34 Wang, C., Cheng, L., Liu, Y., Wang, X., Ma, X., Deng, Z., Li, Y. \& Liu, Z. Imaging-guided $\mathrm{pH}$-sensitive photodynamic therapy using charge reversible upconversion nanoparticles under near-infrared light. Adv. Funct. Mater. 23, 3077-3086 (2013).

35 Chen, Q., Wang, C., Cheng, L., He, W., Cheng, Z. \& Liu, Z. Protein modified upconversion nanoparticles for imaging-guided combined photothermal and photodynamic therapy. Biomaterials 35, 2915-2923 (2014).

36 Bratasz, A., Kulkarni, A. C. \& Kuppusamy, P. A highly sensitive biocompatible spin probe for imaging of oxygen concentration in tissues. Biophys. J. 92, 2918-2925 (2007).
37 Rieffel, J., Chen, F., Kim, J., Chen, G., Shao, W., Shao, S., Chitgupi, U., Hernandez, R., Graves, S. A., Nickles, R. J., Prasad, P. N., Kim, C., Cai, W. \& Lovell, J. F. Hexamodal imaging with porphyrin-phospholipid-coated upconversion nanoparticles. Adv. Mater. 27, 1785-1790 (2015)

38 Guan, M., Qin, T., Ge, J., Zhen, M., Xu, W., Chen, D., Li, S., Wang, C., Su, H. \& Shu, C. Amphiphilic trismethylpyridylporphyrin-fullerene $\left(\mathrm{C}_{70}\right)$ dyad: an efficient photosensitizer under hypoxia condition. J. Mater. Chem. B 3, 776-783 (2015).

39 Mai, H., Zhang, Y., Si, R., Yan, Z., Sun, L., You, L. \& Yan, C. High-quality sodium rareearth fluoride nanocrystals: controlled synthesis and optical properties. J. Am. Chem. Soc. 128, 6426-6436 (2006).

40 Yin, A., Zhang, Y., Sun, L. \& Yan, C. Colloidal synthesis and blue based multicolor upconversion emissions of size and composition controlled monodisperse hexagonal $\mathrm{NaYF}_{4}: \mathrm{Yb}, \mathrm{Tm}$ nanocrystals. Nanoscale 2, 953-959 (2010).

(c) (i) This work is licensed under a Creative Commons Attribution 4.0 International License. The images or other third party material in this article are included in the article's Creative Commons license, unless indicated otherwise in the credit line; if the material is not included under the Creative Commons license, users will need to obtain permission from the license holder to reproduce the material. To view a copy of this license, visit http:// creativecommons.org/licenses/by/4.0/

Supplementary Information accompanies the paper on the NPG Asia Materials website (http://www.nature.com/am) 